\title{
Perubahan Fonem pada Bahasa Jawa ngapak di Kabupaten Kebumen (Sebuah Kajian Fonologi)
}

\author{
Prapti Wigati Purwaningrum \\ Akademi Bahasa Asing Bina Sarana Informatika \\ email : prapti.pwp@bsi.ac.id
}

\begin{abstract}
Cara Sitasi:
Purwaningrum, P. W. (2018). Perubahan Fonem pada Bahasa Jawa ngapak di Kabupaten Kebumen (Sebuah Kajian Fonologi). Wanastra, 10(2), 21-28.
\end{abstract}

\begin{abstract}
The purpose of this analysis is to know some contributing factors of phonem changes in Bahasa Jawa ngapak in Desa Bendungan, Kabupaten Kebumen. The method of this analysis is field research and the data of this analysis are taken from some utterances which uttered by respondence. In collecting the data, writer interviewed the respondence about same words then write the fhonetic transcription of it. The writer found some phoneme changes such as coarticulation process in labialization in 〈tua〉 [tuwa], nasalisation [mb], [nd], and [nf], and glottalisation in [ri?], [ula?], [sapa?]. The next changes are distribution process such as aferesis <hati> [ati], <hujan> [ucan], <rumah> [umah], apokop<ular> [ula?], monophthong <danau> [dano] [au] menjadi [o], and the last process is anaftiksis such as paragog in 〈siku> [sikut. Besides that the writer also found some consonants cluster in Bahasa Jawa Ngapak such as [swiwi], with [r] [kruyu], [mripat], [mrinay],

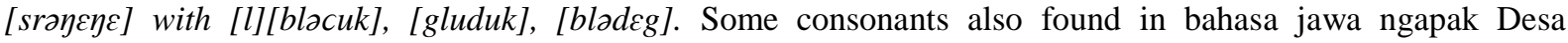
Bendungan kabupaten Kebumen [p], [b], [t], [t], [c], [f], [k], [g], [?], [m], [n], [y], [n], [r], [s], [j], [h], [w], [1]. Besides that some vocals also appear $[\mathrm{i}],[\mathrm{u}],[\mathrm{e}],[\mathrm{\jmath}],[\varepsilon],[\mathrm{o}],[\mathrm{a}]$.
\end{abstract}

Keywords: Perubahan Fonem, Konsonan, Vokal, Konsonan Gabungan, Bahasa Jawa Ngapak Kabupaten Kebumen.

\section{PENDAHULUAN}

Bahasa daerah sebagai salah satu kekayaan budaya yang dimiliki oleh bangsa Indonesia, sudah selayaknya dijaga dan dilestarikan agar tetap terjaga keberadaannya. Melalui usaha pemertahanan bahasa berarti turut menambah serta memperkaya bahasa dan kebudayaan dan bahasa nasional. Bangsa Indonesia memiliki beragam bahasa daerah dan dialek yang berbeda.

Beberapa bahasa daerah seperti jawa, sunda, madura, serta padang merupakan bahasa yang cukup banyak penggunanya. Selain itu masih banyak bahasa daerah lain yang juga tetap harus digunakan, dijaga dan dilestarikan keberadaannya. Namun di masa sekarang tidak sedikit orang tua yang tidak lagi mengenalkan bahasa bahasa daerah pada anakanaknya. Para orang tua berlomba mengenalkan bahasa asing dengan berbagai alasan, sehingga banyak dari anak-anak sekarang tidak mengenal bahasa daerahnya masing-masing. Terkadang rasa miris menyadarkan kembali kepekaan terhadap keberadaan bahasa daerah yang semakin hari semakin terabaikan.

Penelitian bahasa sangat penting dilakukan sebagai usaha pemertahannan bahasa daerah itu sendiri dan sekaligus sebagai cara untuk mengembangkan bahasa nasional. Begitu banyak kajian dalam bidang bahasa dari mulai fonologi, morfologi, sintak, semantik, sosiolinguistik, serta pragmatik serta kajian terapan lainnya yang semuanya sangat menari dan bermanfaat untuk dilakukan.

Kajian fonologi merupakan kajian dasar dalam tingkatan kajian linguistik. Dalam (Chaer 2013:5) disebutkan bahwa fonologi mengkaji tentang bunyibunyi bahasa sebagai hasil akhir dari serangkaian tahap segmentasi terhadap suatu ujaran. Bunyi-bunyi bahasa sebagai satuan terkecil dari ujaran beserta dengan gabungan antarbunyi yang membentuk suku kata. Pendapat lain dikemukakan oleh (kridalaksana 2008:57) merupakan bidang dalam tataran linguistik bunyi-bunyi bahasa menurut fungsinya.

Bahasa jawa merupaka salah satu bahasa daerah yang jumlah pemakaianya lebih banyak dibandingkan dengan bahasa daerah lain. Bahasa Jawa terbagi menjadi beberapa daerah yaitu jawa timur, Jawa tengah dan Daerah istimewa Jogjakarta. Masing-masing daerah tersebut memiliki ciri khas dan juga dialek yang berbeda. Sehingga terkadang dengan penutur menuturkan tuturan maka mitra tutur akan dapat mengidentifikasi dari mana penutur tersebut bersal.

Di jawa tengah khususnya juga memiliki dialek yang berbeda yaitu ada jawa ngapak yang digunakan oleh masyarakat Jawa Tengah dibagian barat dan semakin ke arah timur dialek jawa yang digunakan seamakin halus. Dimulai dari Tegal, Brebes, 
Banyumas, Kebumen, Purworejo, Jogjakarta, Solo, dan Semarang. Kabupaten Kebumen merupakan daerah yang berada diantara kabupaten Banyumas dan Purworejo, sehingga dialek dalam daerah tersebut dipengaruhi perpaduan antara dialek ngapak dari Kabupaten Banyumas dan halus dari Kabupaten Purworejo.

Dalam tulisan ini penulis menggunakan data yang diambil dari tuturan salah satu masyarakat yang tinggal di Desa Bendungan di Kabupaten Kebumen. Dialek bahasa setempat masih cukup kental dipengaruhi dialek ngapak. Penulis memberikan 253 kosa kata dalam bahasa Indonesia, lalu responden menjawab menggunakan bahasa daerah tersebut.

Menurut Chaer fonologi merupakan gabungan dari kata fon 'bunyi' dan logi yang berarti ilmu, yang berarti fonologi merupakan bagian dari kajian linguistik yang mengkaji, membahas, membicarakan, menganalisis bunyi-bunyi bahasa yang diproduksi oleh alat ucap manusia.

Pijakan berikutnya yaitu beberapa hal yang mempengaruhi perubahan bunyi atau fonem. Masih dalam (Chaer 2013: 96-105) di dalam praktik bertutur fonem atau bunyi atau bahasa tidak berdiri sendiri melainkan saling berkaitan. Oleh karena itu secara fonetis maupun fonemis akibat dari saling berkaitan maka bunyi itu bisa saja berubah. Jika perubahannya tidak mempengaruhi identitas fonemnya berubah maka perubahan itu bersifat fonetis, tapi jika perubahan tersebut mempengaruhi identitas fonemnya berubah maka fonem itu bersifat fonemis. Proses perubahan fonem dipengaruhi oleh beberapa hal yaitu adanya koartikulasi, perubahan morfologi, akibat lingkungan, distribusi, dan perkembangan sejarah.

Menurut (Chaer 2013:97) proses perubahan itu dapat terbagi dalam beberapa bentuk yang antara lain:

1. Akibat adanya koartikulasi

a. Labialisasi

Proses pembulatan bentuk bibir ketika artikulasi primer berlangsung.

Contoh:

$<$ tujuan>, bunyi [t] bunyi terdengar [tw]

b. Glotalisasi yaitu bunyi sertaan yang dihasilkan dengan cara glotis ditutup sesudah bunyi utama diucapkan sehingga terdengar bunyi sertaan. Misal: bunyi [a] pada kata <akan> terdengar menjadi [a?kan].

c. Nasalisasi bunyi sertaan yang dihasilkan dengan cara memberikan kesampatan arus udara melalui rongga hidung sebelum atau sesudah bunyi utama diucapkan, sehingga terdengar bunyi sertaan [m], terjadi pada konsonan hambat bersuara yaitu [b], [d], dan $[\mathrm{g}]$ sehingga menjadi [mb], [nd], dan [kg].

\section{Akibat distribusi}

Netralisasi yaitu proses hilangnya kontras antara dua buah fonem yang berbeda. Misalnya bunyi [p] pada kata <jawab> dilafalkan menjadi bunyi [p] dan juga sebagai [b].

3. Akibat perkembangan sejarah

Hal ini diakibatkan oleh pemakaian sejumlah unsur leksikal di dalam masyarakat dan budaya.

a. Kontraksi (peenyingkatan)

Proses menghilangkan sebuah bunyi atau lebih pada sebuah unsur leksikal.

1) Aferesis

Yaitu proses penghilangan satu fonem atau lebih pada awal kata.

2) Apokop

Proses penghilangan satu fonem atau lebih

b. Monoftongisasi

Proses ini terjadi akibat adanya perubahan dua vokal atau gugus vokal menjadi sebuah vokal.

c. Anaftiksis

Proses penambahan bunyi vokal diantara dua konsonan dalam sebuah kata atau penambahan sebuah konsonan pada sebuah kata tertentu.

1) Paragog

Ini merupakan proses penambahan bunyi pada posisi akhir kata.

\section{METODOLOGI PENELITIAN}

Menurut Sudaryanto, Metode deskriptif menyarankan bahwa penelitian yang dilakukan semata-mata berdasarkan pada fakta yang ada atau fenomena yang memang secara empiris hidup pada penutur-penuturnya, sehingga dihasilkan atau dicatat berupa pemberian bahasa seperti potret, paparan seperti apa adanya. Dengan metode deskriptif, 
penelitian dilakukan semata-mata berdasarkan fakta atau fenomena yang memang hidup pada penuturnya. Dalam hal ini, metode dekriptif memberikan gambaran yang objektif tentang fonologi bahasa jawa di Desa Bendungan kabupaten Kebumen yang akan dianalisis sesuai dengan faktor pemakaian sebenarnya dari bahasa itu sendiri.

Pendekatan penelitian yang digunakan dalam penelitian ini adalah menggunakan pendekatan kualitatif. Penelitian kualitatif merupakan bentuk penelitian yang menggambarkan suatu keadaaan dengan uraian. Data yang dikumpulkan berupa katakata (Moleong, 2005:11). Oleh karena itu, data yang akan dikumpulkan mengacu pada makna atau pemahaman terhadap interkasi terhadap konsep data yang dianalisis. Dengan demikian data dianalisis dalam bentuk uraian transkripsi.

Pendekatan kualitatif memiliki ciri-ciri berlatar alamiah, bersifat deskriptif, lebih mengutamakan proses daripada hasil, dan analisis data bersifat induktif (Bogdan dan Biklen, 1982 dalam Djajasudarma,1994).

Berlatar alamiah, maksudnya data penelitian bersumber dari peristiwa-peristiwa komunikasi dan situasi alamiah yang berlangsung di masyarakat setempat.

Bersifat deskriptif, maksudnya data dikumpulkan berbentuk deskripsi wacana. Data dilengkapi dengan konteks terjadinya interaksi. Pendeskripsian konteks diupayakan hingga menyentuh hal-hal kecil, seperti waktu, tempat, dan kedudukan partisipan. Hasil analisis data dipaparkan sesuai dengan temuan di lapangan.

Data dan Sumber Data

a. Data

Data dalam penelitian ini berupa bunyi-bunyi bahasa dalam bahasa Jawa di desa Bendungan Kabupaten Kebumen.

b. Sumber Data

Sumber data dalam penelitian ini adalah bahasa yang dituturkan oleh penutur jati bahasa Jawa yang diperoleh melalui pengamatan dan pencatatan lapangan secara langsung. Subjek penelitian yang dipilih dalam penelitian ini adalah penutur jati bahasa tersebut. Namun, tidak semua masyarakat asli penutur bahasa setempat mempunyai kedudukan yang sama. Oleh karena itu, untuk mendapatkan data yang valid diperlukan seorang informan.

\section{HASIL DAN PEMBAHASAN}

Tabel 1. Hasil Analisis Perubahan Fonem Pada Bahasa Jawa Ngapak di Desa Bendungan Kab. Kebumen.

\begin{tabular}{|c|c|c|c|c|c|c|c|}
\hline \multicolumn{8}{|c|}{ Perubahan Fonem } \\
\hline \multicolumn{3}{|c|}{ koartikulasi } & Distri & \multicolumn{4}{|c|}{ Perkembangan Sejarah } \\
\hline \multirow{2}{*}{$\begin{array}{l}\text { la } \\
\mathbf{b}\end{array}$} & \multirow{2}{*}{$\begin{array}{c}\mathrm{na} \\
\mathrm{s}\end{array}$} & \multirow{2}{*}{ glot } & \multirow[b]{2}{*}{ net } & \multicolumn{2}{|c|}{ kontraksi } & \multirow{2}{*}{$\underset{\mathrm{f}}{\mathrm{mono}}$} & \multirow{2}{*}{$\begin{array}{c}\text { anaf } \\
\begin{array}{c}\text { parago } \\
\mathrm{g}\end{array}\end{array}$} \\
\hline & & & & $\begin{array}{c}\text { aferesi } \\
\mathrm{s}\end{array}$ & $\begin{array}{c}\text { apoko } \\
\text { p }\end{array}$ & & \\
\hline 1 & 9 & 12 & 1 & 3 & 1 & 2 & 1 \\
\hline
\end{tabular}

Catatan:

1. No : Nomor

2. Ina : Indonesia

3. Japak : Jawa Ngapak

4. Lab : Labialisasi

5. Nas : Nasalisasi

6. Glot : Glotalisasi

7. Net: Netralisasi

8. Monof : Monoftongisasi

9. Anaf : Anaftiksis

Dalam tulisan ini penulis menggunakan data sebanyak 253 tuturan dalam Bahasa Jawa ngapak di Desa Bendungan Kabupaten Kebumen. Data data tersebut penulis menemukan beberapa proses fonologi yang terjadi, dianatarnya:

1. Proses Koartikulasi

Menurut Chaer (2013:96) Proses ini terjadi karena saat artikulasi primer memproduksi bunyi pertama berlangsung, alat-alat ucxap sudah mengambil ancang-ancang untuk memproduksi bunyi selanjutnya.

a. Labialisasi

Proses ini terjadi saat ada pembulatan bentuk bibir saat artikulasi primer berlangsung.

Dalam bahasa Indonesia kata Tua saat dituturkan dalam bahasa Jawa ngapak menjadi [tuwa]. [t] adalah bunyi alpikoalveolar, tapi pada kata <tua> [t] disusul dengan $[\mathrm{u}]$ yang merupakan vokal bundar, maka [t] denganpembulatan bibir maka seolah muncul bunyi [tw]. Jadi kata $<$ tua > dilafalkan menjadi [tuwa].

b. Nasalisasi. 
Merupakan proses bunyi sertaan yang dihasilkan dengan cara memberikan kesempatan arus udara melalui rongga hidung sebelum atau sesaat bunyi tersebut diucapkan. Bunyi sertaan [m] dan [n] pada [mb], [nd], dan [nJ].

[mb]

kata <malam> dalam bahasa jawa ngapak <bengi> namun pada saat dituturkan ada arus udara melalui rongga hidung sehingga terdengar bunyi sertaan [m] [mbəni]. Bunyi yang sama juga terdapat pada kata <busek> dan <nangburi>

[nd]

Kata <lihat> dalam bahasa jawa ngapak $<$ deleng> namun saat dituturkan ada arus udara melalui rongga hidung sehingga terdengar bunyi sertaan [n] [ncələy]. Bunyi yang sama juga ditemukan pada kata <damu > [ncamu].

\section{[nf]}

Kata <duduk> dalam bahasa jawa ngapak <jagong> namun saat dituturkan akan terdengar bunyi sertaan [n] [nfagon]. Bunyi serupa juga terdapat pada <jepit>, [nfəpit], <nangjaba> [naynfaba], dan <nangjero> [naynfəro].

\section{c. Glottalisasi}

Bunyi sertaan yang muncul saat glotis tertutup sesudah bunyi utama sehingga terdengar bunyi [?]. Seperti pada kata $\langle$ Duri $\rangle$, <kutu>, <kamu> saat dituturkan dalam bahasa Jawa ngapak akan terdengan bunyi glottal [?] bunyi [i] pada [ri?], bunyi [a] pada [tuma?], dan bunyi [æ] pada [kowæ?]. Berdasarkan data penelitian ini, bunyi glottal cukup banyak ditemukan diantaranya pada bunyi [ula?], [dawa?], [bojo?], [icu?], [kaæ?], [sapa?], [apa?], [təka?], [ora?].

\section{Proses Distribusi}

Menurut Chaer (2013:99) proses ini merupakan saat dimana letak suatu bunyi dalam satu satuan ujaran.

\section{a. Netralisasi}

Situasi ini terjadi karena hilangnya kontras antara dua buah fonem yang berbeda. Bunyi [t] pada kata <babat> dapat dilafalkan sebagai bunyi [t] dan [d], sehingga bisa dilafalkan [babat] dan [babac].
3. Perkembangan sejarah

a. Proses kontraksi (penyingkatan)

Masih dalam (Chaer 2013:103) proses ini menghilangkan sebuah bunyi atau lebih pada seluruh unsur leksikal.

1) Aferisis merupakan proses penghilangkan satu fonem atau lebih pada awal kata.

Pada kata $<$ hati $>$ jika dituturkan dalam bahasa jawa ngapak akan terdengar [ati] pada pelafalan ini terjadi penyingkatan dari kata <hati> dituturkan menjadi bunyi [h] hilang [ati]. Proses penyingkatan ini juga terjadi pada bunyi [ucan] dan [umah].

2) Apokop adalah proses penghilangan satu fonem atau lebih pada akhir kata.

Pada kata <ular> dalam bahasa jawa ngapak dituturkan menjadi [ola?] disini bunyi $[\mathrm{r}]$ hilang dan pelafalannya seperti muncul bunyi glotal.

b. Monoftongisasi

Merupakan proses perubahan dua buah vokal atau gugus vokal menjadi sebuah vokal. Pada kata <danau> dilafalkan dalam bahasa jawa ngapak akan terdengar menajdi [dano]. Dalam perubahan bunyi tersebut terdapat perubahan bunyi dari dua buah vokal [au] menjadi satu vokal yaitu bunyi [0] maka menjadi [dano].

c. Anaftiksis

Paragog adalah Proses yang terjadi saat ada penambahan bunyi vokal diantara dua konsonan dalam kata atau penambahan konsonan pad akata tertentu. Pada kata <siku> jika dilafalkan dalam bahasa jawa menjadi [sikut]. Dalam bunyi tersebut terjadi penambahan bunyi konsonan di akhir kata dari [siku] dalam bahasa jawa ngapak menjadi [sikut] yaitu terjadi penambahan bunyi [t].

Selain itu dalam bahasa jawa ngapak di Desa Bendungan kabupaten Kebumen ditemukan beberapa bunyi konsonan gabungan / consonant Cluster. Diantaranya:

1. gabungan konsonan $/ \mathrm{r} /$

/mr/ pada bunyi [mripat] dan [mrinay] 
/kr/ pada bunyi [kruyu]

/sr] pada bunyi [srəyenc]

2. gabungan konsonan mengandung /1/

/bl/ pada bunyi [bləcuk] dan [blədeg]

/gl/ pada bunyi [gluduk]

3. gabungan konsonan mengandung /w/

/sw/ pada bunyi [swiwi]

Berikut distribusi fonem konsonan dalam

bahasa Jawa Ngapak di Desa Bendungan

Kabupaten Kebumen

Tabel 2. Distribusi Fenom Bahasa Jawa Ngapak Di Desa Bendungan Kabupaten Kebumen: Konsonan

\begin{tabular}{|c|c|c|c|c|c|c|c|c|c|c|c|}
\hline $\begin{array}{l}\text { DISTRIF } \\
\text { KONSOI }\end{array}$ & $\begin{array}{l}\text { USI FON } \\
\text { JAN }\end{array}$ & М ВАНА & A JA & NGA & K I & ESA & NDU & $\mathbf{N} \mathbf{K} A$ & PATEN & KEB & \\
\hline PLOSIF & [p] & [b] & {$[\mathrm{t}]$} & [d] & [t] & [c] & {$[\mathfrak{j}]$} & {$[\mathrm{k}]$} & [g] & [?] & KET \\
\hline$\# \mathrm{C}_{-}$ & & & & & & & & & & & \\
\hline data & [papat] & [balun] & [tələs] & [dano] & & [colan] & [†ənəy] & [kodol] & [gədan] & & \\
\hline Makna & empat & tulang & basah & Danau & & Main & nama & Tumpul & pisang & & \\
\hline Nomor & 58 & & & 37 & & 241 & & 97 & 103 & & \\
\hline _C & & & & & & & & & & & \\
\hline data & [njəpit] & [abay] & [watu] & [bləd $\varepsilon g]$ & [sitik] & [wəci] & [crifi] & [təkən] & [cagin] & & \\
\hline Makna & Jepit & Merah & batu & Kilat & & Takut & Jari & Tongkat & Daging & & \\
\hline Nomor & 247 & 123 & & 87 & & 228 & 15 & 88 & & & \\
\hline _ $\mathrm{C \#}$ & & & & & & & & & & & \\
\hline data & [landəp] & [tunfləb] & [ilat] & [babad] & & & & [lamuk] & [blədeg] & [ri?] & \\
\hline Makna & tajam & Tikam & lidah & babat & & & & awan & kilat & duri & \\
\hline
\end{tabular}

Tabel 3. Distribusi Fonem Bahasa Jawa Ngapak Didesa Bendunan Kabupaten Kebumen : Konsonan

\begin{tabular}{|c|c|c|c|c|}
\hline \multirow[b]{2}{*}{ NASAL } & \multicolumn{4}{|c|}{$\begin{array}{l}\text { DISTRIBUSI FONEM BAHASA JAWA NGAPAK DI DESA } \\
\text { BENDUNGAN KABUPATEN KEBUMEN: KONSONAN }\end{array}$} \\
\hline & {$[\mathrm{m}]$} & {$[\mathrm{n}]$} & {$[\mathrm{n}$} & [y] \\
\hline \multicolumn{5}{|l|}{$\# \mathrm{C}_{-}$} \\
\hline data & [mbəyi] & [nəクən] & [nokot] & [yomon] \\
\hline makna & malam & Kanan & Gigit & Bicara \\
\hline no data & 100 & 116 & 143 & 198 \\
\hline \multicolumn{5}{|l|}{ _C } \\
\hline data & [mambu] & [lanay] & [ajar] & [kruyu] \\
\hline makna & $\mathrm{Bau}$ & Laki-laki & Baru & Dengar \\
\hline no data & 117 & 174 & 157 & 195 \\
\hline \multicolumn{5}{|l|}{ _ C\# } \\
\hline data & [antəm] & [təkən] & & [lanay] \\
\hline makna & Pukul & Tongkat & & Laki-laki \\
\hline no data & 206 & 88 & & 174 \\
\hline
\end{tabular}


Tabel 4. Distribusi Fonem Bahasa Jawa Ngapak Didesa Bendunan Kabupaten Kebumen : Konsonan

\begin{tabular}{lc}
\hline & $\begin{array}{c}\text { DISTRIBUSI FONEM BAHASA JAWA NGAPAK DI } \\
\text { DESA BENDUNGAN KABUPATEN KEBUMEN: } \\
\text { TRIL }\end{array}$ \\
\hline KONSONAN
\end{tabular}

Tabel 5. Distribusi Fonem Bahasa Jawa Ngapak Didesa Bendunan Kabupaten Kebumen : Konsonan

\begin{tabular}{|c|c|c|}
\hline \multirow[b]{2}{*}{ FRIKATIF } & \multicolumn{2}{|c|}{$\begin{array}{l}\text { DISTRIBUSI FONEM BAHASA JAWA NGAPAK DI DESA } \\
\text { BENDUNGAN KABUPATEN KEBUMEN: KONSONAN }\end{array}$} \\
\hline & {$[\mathrm{s}]$} & {$[\mathrm{h}]$} \\
\hline \multicolumn{3}{|l|}{$\# \mathrm{C}_{-}$} \\
\hline data & [sirah] & \\
\hline makna & Kepala & \\
\hline no data & 1 & \\
\hline \multicolumn{3}{|l|}{$\mathbf{C}_{-}$} \\
\hline data & [bosok] & \\
\hline makna & Busuk & \\
\hline no data & 116 & \\
\hline \multicolumn{3}{|l|}{ _ C\# } \\
\hline data & [yərəs] & [gumoh] \\
\hline makna & Kotor & Muntah \\
\hline no data & 12 & 205 \\
\hline
\end{tabular}

Tabel 6. Distribusi Fonem Bahasa Jawa Ngapak Didesa Bendunan Kabupaten Kebumen : Konsonan

\begin{tabular}{ll}
\hline & $\begin{array}{c}\text { DISTRIBUSI FONEM BAHASA JAWA NGAPAK DI DESA } \\
\text { BENDUNGAN KABUPATEN KEBUMEN: KONSONAN }\end{array}$ \\
\hline \#C_ & {$[\mathrm{w}]$} \\
\hline data & {$[$ wətə) $]$} \\
\hline makna & Perut \\
\hline no data & 24 \\
\hline C_ & \\
\hline data & {$[$ kuwuy $]$} \\
\hline makna & Pelangi \\
\hline
\end{tabular}




\begin{tabular}{ll}
\hline no data & 76 \\
\hline C $\#$ & \\
\hline data & \\
\hline makna & \\
\hline no data
\end{tabular}

Tabel 7. Distribusi Fonem Bahasa Jawa Ngapak Didesa Bendunan Kabupaten Kebumen : Konsonan

\begin{tabular}{ll}
\hline & $\begin{array}{c}\text { DISTRIBUSI FONEM BAHASA JAWA NGAPAK DI DESA } \\
\text { BENDUNGAN KABUPATEN KEBUMEN: KONSONAN }\end{array}$ \\
\hline \#C_ & {$[1]$} \\
\hline data & {$[$ lara $]$} \\
\hline makna & Sakit \\
\hline no data & 32 \\
\hline C__ & \\
\hline data & {$[$ bələt] } \\
\hline makna & Lumpur \\
\hline no data & 43 \\
\hline C\# & {$[$ sikil] } \\
\hline data & Kaki \\
\hline makna & 29 \\
\hline no data & \\
\hline
\end{tabular}

\section{KESIMPULAN}

Simpulan dari analisis ini adalah penulis menemukan beberapa proses fonologi yang terjadi dalam bahasa Jawa ngapak di Kabupaten Kebumen. Peroses tersebut meliputi adanya proses koartikulasi yaitu nasalisasi, labialisasi, dan glotalisasi. Proses berikutnya yang penulis temukan adalah kontraksi dengan adanya aferesis dan apokop. Selanjutnya proses distribusi melalui netralisasi juga ditemukan, monoftongisasi, dana anafiksis jenis paragog.

Dalam bahasa jawa ngapak di kabupaten Kebumen ini cukup banayk ditemukan proses netralisasi. Pada umumny proses nasalisasi yang sering terjadi pada pada bunyi [mb], [nd], dan [kg], tapi pada bahasa jawa ngapak ditemukan proses nasalisasi [mb], [nd] dan [nf].

Bunyi konsonan yang muncul pada bahasa jawa ngapak di desa Bendungan kabupaten Kebumen adalah [p], [b], [t], [t], [c], [f], [k], [g], [?], [m], [n], $[\mathrm{y}],[\mathrm{n}],[\mathrm{r}],[\mathrm{s}],[\mathrm{j}],[\mathrm{h}],[\mathrm{w}],[\mathrm{l}]$.

sedangkan vokal yang muncul meliputi

[i]: [irup] 10

[u]:[kupin] 4

[e]: [lambe] 6 [ə]:[yərəs] 12

[ع]: [bləd $\varepsilon g] 87$

[o]: [kodol] 97

[a]: [abay] 123

\section{REFERENSI}

Chaer, Abdul. 2013. Fonologi Bahasa Indonesia. Jakarta: Rineka Cipta.

Kridalaksana, Harimurti. 2008. Kamus Linguistik. Jakarta: PT. Gramedia.

Kusuma, Eka. 2013. Kajian afonologi dan Leksikon Bahasa Jawa Di Desa Wanayasa kecamatan Wanayasa Kabupaten Banjarnegara. Jurnal Pendidikan, Bahasa, sastra dan Budaya Jawa(Vol.03).http://ejournal.umpwr.ac.id/i ndex.php/aditya/article/view/733

Schane, Sanford A. 1973. Generative Phonology. Prentice Halle, Englewood Clliffts

Sudaryanto. (2015). Metode dan Teknik Analisis Bahasa: Pengantar Penelitian Wahana Kebudayaan Secara Linguistis. Yogyakarta: Duta Wacana University Press. 
PROFIL PENULIS

RIWAYAT HIDUP/CURRICULUM VITAE

Nama/Complete Name :Prapti Wigati

Purwaningrum

Institusi/Institution $\quad$ : ABA BSI Jakarta

Pendidikan/Education $\quad$ : S2 Linguistik

Minat Penelitian/Research Interest: Pragmatik 